\title{
Lexical Cohesive Chain in Research Article: A Case Study from Ecological Views
}

\author{
Jiayu Wang, Yi Zhang \\ Northwestern Polytechnical University \\ China
}

\begin{abstract}
This case study investigates the significance of lexical cohesive chains (LCCs) in research articles (RAs) from ecological views. Through randomly selecting a research article from Applied Linguistics, this research analyzes what the features of LCCs are and how ecological views are reflected from the uses of LCCs. By manually coding the lexical cohesive devices, the LCCs were analyzed sentence by sentence. The results show that repetitions are the most frequently used devices and the bases of primary LCCs as well. Primary LCCs thread through the whole article and mainly carry the keywords in the research. In contrast, the secondary is more dynamic, because it helps transmit new information. Ultimately, it is projected that under the guidance of ecological views, situated view, interactive view, dynamic view, and holistic view, both writers and readers become more aware of the LCCS' importance to the coherence of RAs.
\end{abstract}

Keywords: Lexical Cohesive Chain; Research Article; Ecological View

\section{Introduction}

The research on lexical cohesion is initiated by Halliday \& Hasan (1976) under the framework of Systemic Functional Linguistics. It is classified as one of the textual functions of language. Repetition, hyponymy, antonymy, synonymy, meronymy, and collocation are its constituents (Halliday \& Hasan, 1976; Hasan, 1984). Compared with grammatical cohesion like references, ellipses, connectives, etc., lexical cohesion has two characteristics. First, it encodes semantic meanings. Repetition, as a lexical cohesive device, always refers to the keywords in a text, because only the essential information is frequently repeated. Second, lexical cohesion devices can form cohesive chains (Tanskanen, 2006), bonds (Hoey, 1991), or ties (Halliday \& Hasan, 1976) threading through the whole text. For this reason, the appropriate use of lexical cohesion promotes the coherence of the text. As for writers, the coherence of the text enables readers to catch their meanings easily. Coherence is also a mental representation of readers (van Dijk, 2008). As for readers, following the cohesive chains is easy to keep abreast with the new information.

Only a few research examine lexical cohesive chain (LCC) in detail. Even though some scholars cast some lights on it (Gutwinski, 1976; Morris \& Hirst, 1988; Tanskanen, 2006), they did not underline the importance of LCCs. The reason may be that previous research neglect how LCCs connect information throughout the whole text. Therefore, in order to make up the gap, this case study attempts to analyze an article in a detailed way. Besides, the adoption of an ecological view is to systematically explain how on earth the LCC exert its cohesive functions. Ecological views contain a situated view, interactive view, dynamic view, and holistic view. Language ecology is considered philosophical guidance (He, 2017). The thought can be broadly used to analyze discourses (Garner, 2004), and metaphorically, the discourse itself can be regarded as an ecological system. Consequently, the present case study tries to answer two research questions as follows,

1) What are the features of lexical cohesive chains?

2) How do lexical cohesive chains reflect ecological views?

\section{Theoretical Framework}

\subsection{Lexical Cohesion and Lexical Cohesive Chains}

Lexical cohesion is regarded as a systemic way to connect words for interactive purposes (McCarthy, 1988). The interactions are between writer/speaker and reader/hearer. It seems that most scholars see eye to eye on the definition of lexical cohesion. However, the discrepancies gather at the classification of lexical cohesion. It is also worth mentioning that most classifications are based on Halliday \& Hasan (1976)'s classifications. 
Danes (1987) divided lexical cohesion into three categories which cover relations of familiarity based on identity, set relations and semantic closeness. In essence, these three almost contain the same elements of Halliday \& Hasan (1976)'s. Hoey (1991)'s division includes eight sub-categories. Although it seems that his version is more detailed and operable in empirical research, some of the grammatical cohesion devices like ellipsis and substitutions are also classified into lexical cohesion as well. It probably confuses the users of lexical cohesion, because lexical cohesion devices usually encode semantic meanings' exchange. For instance, using "it" to substitute a content word does not refer to concrete meanings. Martin (1992) put forward a classification including three categories: taxonomic, nuclear and activity sequence relations. Except for the overlapped parts with Halliday \& Hasan (1976)'s classification, activity relations emphasize the importance of context. However, these three types are intertwined with each other, which could be a big block in the practical analysis. Still, there are other classifications derived from Halliday \& Hasan (1976)'s (Sinclair, 2004; Tanskanen, 2006). Based on the comparison, Halliday \& Hasan (1976)'s is probably more lucid and workable.

Nevertheless, it does not indicate that their version is flawless. There are still inevitable problems in Halliday \& Hasan (1976)'s classification. The most salient one is that the working definition of collocation is vague. Just as Tanskanen (2006) mentioned, most researchers avoid examining collocation, because it is difficult to define. Collocation almost includes any co-occurring items. To discern collocation requires that readers need to activate their encyclopedic information (Carston, 2012) and fully understand the context. Although Tanskanen (2006) classified collocation into three types, ordered set, activity-related collocation and elaborative collocation, the process of recognizing collocation is still complicated. It demands readers to build cognitive frames, and the very first step to discern frames is to find out its trigger. For this reason, this method seems not to be concise either. To conclude, till now, collocation is still a "rag bag" (Hoey, 1991). Therefore, in the current case study, the rag bag is not illustrated.

When it comes to LCC, it is basically a group of related words around the same topic (Morris \& Hirst, 1988), or a pair of related lexical items (Halliday and Hasan, 1976). But the occurrences of closed-class words such as pronouns and propositions were not counted in (Halliday and Hasan, 1976). Moreover, Zhang (2006) declared that repetition was the main base of lexical chains. Besides, the importance of LCC has been highlighted by Halliday (1985). They are demanded to form text. Analyzing cohesive chains is, in essence, examining the texture of the article. In the current research, cohesive chains are the lexical "threads" in the whole text or the local parts of the text. They provide readers with lexical hints, and because of that, the text becomes predictable.

\subsection{Research Articles}

The reason why this case study probes into a research article (RA) is that, compared with other types of texts, there are much more lexical cohesion devices than the grammatical ones (Hyland, 2013). In such cases, successfully receiving writers' information relies on readers' understandings of lexical cohesion. From this point of view, RAs can be a representative among various types of texts. It is also more meaningful to further examine LC in RAs. The other reason is that RA has relatively strict rhetoric structure compared with other genres. The prototypical type (Guinda, 2015) of the structure is Introduction, Methodology, Results, Discussion/conclusion (IMRD) (Swales, 1990). Since each sub-section has its characteristics and features in RA, it helps scrutinize how on earth lexical cohesion is used in detail and makes it possible to analyze the local chains in sub-parts of RAs. Simply speaking, the introduction section is mainly for establishing the context of the paper and motivating readers to discover the research (Hyland, 2000). As for Methodology, it is like a "checklist" (Myers, 1985) or "procedural formulae" (Knorr-Cetina, 1981). The results mainly work for reporting the outcome of a study. Besides, a discussion is always put together with a conclusion since they had two same moves, that is, evaluating study and deductions from the research (Yang, 2006). In addition, RAs are also the most representative discourse in a specific discipline. To research on RAs is an efficient way to know a field.

\subsection{Ecological View}

As Part 1 mentions that ecological view is a philosophical thought, it underlines that human beings are parts of nature (Steffensen \& Fill, 2014), which is a way of ecological thinking. Ecological thinking can be broadly applied in different areas beyond its origins (Garner, 2004). It is why in the current study, ecological views are adopted. Based on Garner (2004)'s interpretation of ecological thinking. There are four ecological views, situated view, holistic view, dynamic view, and interactive view. Situated view emphasizes the importance of setting or context. In the present research, RAs are the settings in which language phenomenon like LCCs appears. 
Holistic view means that any linguistic or language components cannot be separated from its use in actual settings. For instance, the examination of LCCs must rely on the holistic meanings of the whole text instead of the local information in sub-sections. The RA is a coherent whole. When it comes to dynamic view, it implies that language in use is always changing so that new information can enter. The last one is the interactive view. It reveals that the use of language involves different subjects, and they exchange their information during the communication process. For example, the writers' uses of LCC are not for themselves but readers. The uses enable readers to receive writers' information step by step.

\section{Methodology}

\subsection{Sample Selection}

One article, titled "Implicit and Explicit Cognitive Processes in Incidental Vocabulary Acquisition", is randomly selected from Applied Linguistics, one of the most influential journals in the field of applied linguistics. It records an empirical research on second language learners. The research aim is to examine the implicit and explicit strategies that the users draw on to learn new vocabulary in the reading tasks. In addition, it rigorously follows the IMRD structure. The word numbers in each section are 2724 in Introduction, 2217 in Methodology, 2098 in Results and 2304 in Discussion/conclusion. In total, the word count is 9343. What is more, there are 79 sentences, 39 sentences, 69 sentences, and 68 sentences respectively in the IMRD sections. There are 255 sentences in this article.

\subsection{Coding of Lexical Cohesion}

Halliday \& Hasan (1976) only provided rough instructions of each lexical cohesion, although Hasan (1984) and Halliday (1985) further revised their theories. It is still necessary to borrow explicit definitions of lexical cohesion devices from the field of lexical semantics. Repetition helped establish the relationships between sentences (Winter, 1979), and could even organize book-length texts. In terms of LC's features, the repetition of functional words was neglected. While repetition does not strictly restrict that only the same words can be counted as repetition, the words sharing the same content morphemes are also repetition devices. With the exception of the open-class words like adjectives, adverbs, verbs, and nouns, repetition also includes acronyms, count nouns \& mass nouns, lexical verbs, lexical bundles, and name. Lexical bundles always appear as keywords bundles in RAs. Synonymy implies the overlapping semantic meanings, but it is not always fully intersubstitutable (Edmonds \& Hirst, 2002). Researchers took advantage of questionnaires (Liu \& Zhong, 2016) or corpora (Divjak and Gries, 2006) for finding a common sense on such a "slippery" concept. Absolute synonymy can be discerned easily, and they are the most frequently-used pairs. The meaning potential synonym is another type of LC, whose meanings are not determined by the discourse in which they appear. For instance, "study" and "research" are meaning potential pairs. On the contrary, communication potential is the opposite of meaning potential. It represents context-dependent synonymy pairs. For instance, "participants" is equal to "Chinese students" or "Chinese young adults". They refer to the same group of people in the specific research discourse.

Antonymy was divided into three main types, binary gradable, binary non-gradable, and multiple antonyms (Lyons, 1977). Gradable antonyms contain polar antonyms, committed antonyms, and asymmetrical antonyms. Pairs like "cold" and "hot" are two poles, so they are polar antonyms, while "warm" and "cool" locate in the middle part of two poles, so they belong to committed antonyms. In non-gradable antonymy, three sub-types are also included in. For instance, it is impossible to find a state between "language-related" and "non-languagerelated". They are thought of as complementariness. Perspectival opposition usually refers to real-world relationships between people. Pairs like "father-mother" and "husband-wife" are the typical examples. Directional opposition includes words between both static and dynamic state. Pairs like "south-north" and "teaching-learning" are all directional oppositions.

Meronymy not only includes the "part-whole" relationship but "part-part" pairs as well. Geeraerts (2010) mainly sorted out four types of meronymy, components-entity, material-object, action-activity, and member-collocation. During the tagging procession, it is found that action-activity meronymy pairs frequently occur in Methodology. In addition, co-meronymy pairs are also shown in this sentence. However, since the essence of meronyms is about the relationship between "part and whole", co-meronymy is a make-up for the situation when the "whole" is absent. The priority should be given to the "part-whole" relationship, so co-meronymy pairs are not counted in once "part-whole" meronymy pairs appear. 
Hyponymy is relatively a less complicated term. It is coined as a sub-property or a super-property. When hyponymy occurs, there is always a signal like "kind of" or "type of". A "pigeon" is a kind of "bird". They are "upper hyponym" with "lower hyponym". As what is analyzed above in meronymy, when upper terms occurred with the lowers, the co-hyponyms are not counted in.

According to the definitions of lexical cohesion listed above, five different types of LC are highlighted. It is a procession of coding data manually. Although the measure may be low-tech and primary, it is commonly used by researchers in the area of applied linguistics. Especially for the corpus linguist whose first step is to tag the data, highlighting may be an efficient and direct method. Hyland (2006) also adopted highlighters to code different moves in academic writings, which proves that this method is suitable. This method is acceptable. The colors green, yellow, purple, red and blue represent repetition, synonymy, meronymy, hyponymy, and antonymy respectively. Besides, LCCs are also coded manually. Taking Tanskanen (2006)'s research as a reference, the repetition always functions as the bases of LCC and distinguishes one from another. Therefore, during the coding session, repetitions become the entry points of different LCCs.

\subsection{Coding of Lexical Cohesion Chains}

The lexical cohesion sorted out were input in Microsoft Office Excel, in which four sheets were created. They respectively represented IMRD four sections. In each sheet, all content words used in each sentence were shown in the horizontal axis, while the vertical axis represented all sentences in each section. The reason why all content words were extracted was that any of them possibly became one part of LCCs, so the best choice was to record all of the content words. In sum, all sentences in the article were gathered in these four sheets, which ensured that no LCC were neglected. Through using this method, the articles were simplified and how LCC develops became relatively clear. The total numbers of lexical cohesion in each section were listed below used in the whole article.

Table 1 Lexical Cohesion in Each Section of the RA

\begin{tabular}{llllll}
\hline & Repetition & Synonymy & Antonymy & Hyponymy & Meronymy \\
\hline Introduction & 272 & 36 & 24 & 12 & 5 \\
Methodology & 19 & 10 & 0 & 3 & 4 \\
Results & 23 & 10 & 9 & 5 & 1 \\
$\begin{array}{l}\text { Discussion/ } \\
\text { conclusion }\end{array}$ & 8 & 3 & 2 & 0 & 0 \\
In total & 322 & 59 & 35 & 20 & 10 \\
\hline
\end{tabular}

From this table, it shows that repetition was used far more frequently than the other devices in this article, and it occurred mostly in Introduction. It is proved that repetition can function as the bases of LCC due to its overoverwhelming uses in this journal article. Besides, in light of Hoey(1991)'s opinion, repetitions are the "cues" to illustrate how lexical items connect with each other. Therefore, the repetitions are defined as the repetition bases of LCC. Then, the ways to recognize cohesive chains in this study replicated the ones adopted by Zhang (2006) in his research on cohesive chains.

Step 1: Split the text into sentences, and discern the devices used in each sentence.

According to the frequency of the lexical cohesive devices occurring and their positions, they were classified into primary chains or secondary chains.

\section{Step 2: Distinguish the primary from the secondary, determined by two indices.}

The one index is the frequency of the keywords (namely the repetition bases), and the other one is the position where the words appear. They constitute the "intensity" (Zhang, 2006). In the wake of the information's development, the intensity of text varies.

\section{Step 3: Find "repetition bases", since they form lexical cohesive chains.}

The other reason about why repetitions are more important is that they have the strongest cohesion force (Hasan, 1984). That is to say, repetition is the most obvious coherent method even for the readers with low-background knowledge or even for those who barely know the meaning of the lexical items. They can still recognize that words are repeated.

\section{Results}

\subsection{Lexical Cohesion Chains in Introduction}


The table below shows the four primary chains and another four secondary ones in the introduction section.

Table 2. Lexical Cohesive Chains in Introduction

\begin{tabular}{|c|c|c|c|}
\hline $\begin{array}{l}\text { Repetition Base of } \\
\text { Cohesive Chain }\end{array}$ & $\begin{array}{l}\text { Types of } \\
\text { Cohesive } \\
\text { Chain }\end{array}$ & $\begin{array}{l}\text { Words } \\
\text { Frequency } \\
\text { (Times) }\end{array}$ & $\begin{array}{l}\text { Positions Where it Occurs } \\
\text { (Sentence No.) }\end{array}$ \\
\hline $\begin{array}{l}\text { strategy(including } \\
\text { process, processing) }\end{array}$ & Primary & 46 & $\begin{array}{l}5,8,10,12,17,18,25,26,27,28,31,3 \\
4,41,42,43,45,46,47,4950,52,54,5 \\
5,56,57,58,59,60,62,68,69,71,72, \\
73,78,79 ;\end{array}$ \\
\hline vocabulary & Primary & 29 & $\begin{array}{c}1,2,3,4,6,7,8,9,15,16,18,28,29,32 \\
52,58,67,71,75,76,78,79\end{array}$ \\
\hline learner & Primary & 22 & $\begin{array}{l}2,4,5,6,7,14,21,25,28,29,30,33,34 \\
, 36,38,42,44,68,73,74,78 ;\end{array}$ \\
\hline acquisition & Primary & 13 & $\begin{array}{l}1,4,6,7,15,18,25,28,32,58,67,71 \\
, 79\end{array}$ \\
\hline implicit and explicit & Secondary & 11 & $23,26,27,28$ \\
\hline retention & Secondary & 5 & $61,62,63,64,65$ \\
\hline reading & Secondary & 4 & $67,69,72,74$ \\
\hline definition & Secondary & 4 & $4,6,7$ \\
\hline
\end{tabular}

Table 2 introduces the repetition bases of cohesive chains in this section. From a situated view, the combination of both repetitions and synonyms constitute lexical cohesive chains. For example, the "vocabulary" chain also contains its synonyms like "lexical items", "words", "lexical unit", "lexical form" and so on. It can be seen that repetition bases, "strategy", "vocabulary", "learner" and "acquisition" occurred more frequently and threaded through the whole text, compared with another four words which were classified as secondary repetition bases. Although repetition plays the leading role in building lexical cohesive chains, the formation of chains usually depends on the cooperation of various cohesive devices.

There is also a chain formed by both repetition and antonymy. One of the secondary lexical cohesive chains "implicit and explicit" consist of not only its repetitions, and the other important characteristic is that they are antonyms. Through observation, the occurrence of antonymy is highly determined by the contents of this article. If the topics are not about "implicit and explicit" strategies used by learners, antonymy may not be frequently used. The same situation can also be found in terms of the use of hyponymy. In this article, the researcher attempts to test what types of strategies learners may adopt. It is found that "consulting dictionaries" and "inferring meanings" are usually used. For this reason, it is reasonable to consider these two methods as hyponyms of "strategies". As stated in 4.2.4, they are "kinds of" strategies. This example also backs up the opinion introduced above, that is, hyponymy also relies on the contents of a text.

Secondary LCCs are not independent. Mostly, they attach to the primary chains. The secondary chain "implicit and explicit" occurs in the sentences of 26, 27, 28, in the meantime, the "vocabulary" chain is also displayed in the same sentences. The "reading" chain also adheres to the "processing/process" chain, which could be exposed from sentence 60 to 63 .

\subsection{Lexical Cohesive Chains in Methodology}

The details of the lexical cohesive chains used in this part are shown below.

Table 3. LC Chains in Methodology

\begin{tabular}{lllll}
\hline $\begin{array}{l}\text { Repetition Base of } \\
\text { Cohesive Chain }\end{array}$ & $\begin{array}{l}\text { Types of Cohesive } \\
\text { Chain }\end{array}$ & $\begin{array}{c}\text { Words } \\
\text { (Times) }\end{array}$ & Frequency & $\begin{array}{l}\text { Positions Where it Occurs } \\
\text { (Sentence No.) }\end{array}$ \\
\hline vocabulary & Primary & 13 & $1,2,4,7,13,20,23,24,28,35,37 ;$ \\
learner & Primary & 10 & $1,6,7,8,9,15,20,21,38 ;$ \\
French & Secondary & 11 & $1,2,3,4,6,7,11,12,13,15 ;$ \\
text & Secondary & 12 & $2,10,12,13,14,15,16,17 ;$ \\
self-report & Secondary & 3 & $30,31,32 ;$ \\
\hline
\end{tabular}


From the dynamic view, LCCs are not only constrained in a sub-section but also stretch to different sections. It seems that only one repetition base "vocabulary" is reserved in this part. Undoubtedly, vocabulary as the core concept in this research still repeated most frequently. It needs to mention that its synonyms like "lexical items", "words", etc. also occur, and they form the "vocabulary" cohesive chain together. From the dynamic view, this phenomenon shows that LCC is not only constrained in a sub-section but also stretches in different sections.

Table 3 shows that the "learner" chain in the introduction stretches toward this section. The reason is that in Methodology, the writer is obliged to narrow down the broad notions, especially in empirical studies. For instance, in this research, the identities of learners are still vague. This is why the writer substituted learners with participants and introduced the learners' background information who participated in the research. To further examine the "participant" chain, the other components of it need to be mentioned as well. Synonyms like "users", "students", "learners", etc. all adhere to the chain, and it even includes a pair of antonymy, that is, "female" and "male". Besides, the "processing" chain is also embodied in this section. The processing strategies are divided into four different ways, and in order to make them testable, they are replaced by the detailed indices like "level 1"'level 2", "Category I", etc.. These words gathered apprise the readers of how the writers define processing strategies and what on earth the writers try to research on.

In addition, the secondary chains in this part highlight the role that secondary chains usually play in the text. For example, the "French" chain elucidates the identity of the learners who are French as second language users. In the following part, the "text" chain illustrates the reading material used in the study, and the "self-report" is introduced as the research method. From this perspective, following up the development of secondary chains may help readers gain the updated information.

To conclude compared with primary LCC, the secondary reflects more interactive and situated features. The use of secondary LCC should be more scrupulous since it is a process of introducing new information for readers. It easily confuses readers if it is not coherent enough. What is more, from the analysis of Methodology, it shows that every part has its own specific functions. Usually, the writer describes the data and introduces the methods used in research in Methodology. Yang (2006) pointed out that one of the procedures in this section was to define new concepts. It can explain why secondary LLCs like "French", "self-report" appear in this section.

\subsection{Lexical Cohesive Chains in Results}

The repetition bases of primary and secondary chains are shown in Table 4.

Table 4. LC Chains in Results

\begin{tabular}{|c|c|c|c|}
\hline $\begin{array}{l}\text { Repetition Base of } \\
\text { Cohesive Chain }\end{array}$ & $\begin{array}{l}\text { Types } \\
\text { Cohesive } \\
\text { Chain } \\
\end{array}$ & $\begin{array}{l}\text { Words } \\
\text { Frequency } \\
\text { (Times) }\end{array}$ & $\begin{array}{l}\text { Positions Where it Occurs } \\
\text { (Sentence No.) }\end{array}$ \\
\hline $\begin{array}{l}\text { strategy(including } \\
\text { process, processing) }\end{array}$ & Primary & 25 & $\begin{array}{l}1,2,4,6,7,13,23,26,27,30,31,32,38,39, \\
47,48,50,51,52,53,54,55,56,61,68\end{array}$ \\
\hline $\begin{array}{l}\text { learners(participants, } \\
\text { students) }\end{array}$ & Primary & 25 & $\begin{array}{l}4,7,10,12,14,16,19,22,25,26,27,30,32 \\
, 34,40,41,44,45,46,61,67 ;\end{array}$ \\
\hline $\begin{array}{l}\text { vocabulary(including } \\
\text { lexical items, words, } \\
\text { items) }\end{array}$ & Primary & 19 & $\begin{array}{l}1,3,5,8,9,12,13,27,31,32,39,44,50 \\
54,57,67\end{array}$ \\
\hline $\begin{array}{l}\text { knowledge } \\
\text { data }\end{array}$ & $\begin{array}{l}\text { Secondary } \\
\text { Secondary }\end{array}$ & $\begin{array}{l}6 \\
4\end{array}$ & $\begin{array}{l}16,17,18,21,22 \\
46,47,48,49\end{array}$ \\
\hline
\end{tabular}

The first three words in Table 4. are repetition bases of primary chains in Results. Saliently, the three also represent primary chains in the previous two sections, namely Introduction and Methodology. The "strategy" chain is the combination of repetition and synonymy. The word "strategy" is substituted by its synonyms "process" and "processing". Meanwhile, the word "learners" are also replaced by "participants" and "students". From a situated view, in this specific sub-context, the broad term "vocabulary" is not used, instead, its operationalized index is what needs to be examined. Although the words "lexical items", "words", "items", etc are all the synonyms of "vocabulary", they are not used. It seems to be an obvious gap in this chain. From sentence 14 to 26 , during these ten sentences, there is no "vocabulary" or its synonym appearing. The secondary chain "knowledge" fills in the gap. Based on the analysis of the contents, the writer narrows down the "knowledge" into 
an index. Even though "vocabulary" does not occur, it is predicted that readers having finished reading Introduction and Methodology obtain some background information, so the gap may not confuse readers. There are also two secondary chains.

One is, as what is explained above, the "knowledge" chain used to fill the lacunae in the "vocabulary" chain. The other is the "data" chain. Writers concentrate on data analysis in results. The secondary chains supply more new information to the whole text and promote the development of information.

\subsection{Lexical Cohesive Chains in Discussion/conclusion}

Repetition bases of primary and secondary lexical cohesive chain in this section are listed in the table below.

Table 5. LC Chains in Discussion/Conclusion

\begin{tabular}{|c|c|c|c|}
\hline $\begin{array}{l}\text { Repetition Base of } \\
\text { Cohesive Chain }\end{array}$ & $\begin{array}{l}\text { Types of } \\
\text { Cohesive } \\
\text { Chain }\end{array}$ & $\begin{array}{l}\text { Words } \\
\text { Frequency } \\
\text { (Times) }\end{array}$ & $\begin{array}{l}\text { Positions Where it Occurs } \\
\text { (Sentence No.) }\end{array}$ \\
\hline $\begin{array}{l}\text { strategy } \\
\text { (including process, } \\
\text { processing) }\end{array}$ & Primary & 35 & $\begin{array}{l}3,5,7,8,11,13,14,15,17,18,21,22, \\
23,30,40,45,47,50,51,53,54,61, \\
62,63,66,67 ;\end{array}$ \\
\hline $\begin{array}{l}\text { vocabulary (including } \\
\text { lexical items) }\end{array}$ & Primary & 27 & $\begin{array}{l}1,2,3,4,5,9,17,19,22,25,26,33,43 \\
, 45,49,53,56,58,59,60,61,65,68\end{array}$ \\
\hline $\begin{array}{l}\text { learners (including } \\
\text { students) }\end{array}$ & Primary & 19 & $\begin{array}{l}1,2,4,6,11,12,14,15,24,27,37,40 \\
43,54,55,60,61,63\end{array}$ \\
\hline explicit & Secondary & 6 & $14,15,16,20,21,22,23$ \\
\hline implicit & Secondary & 4 & $13,14,16,17$ \\
\hline form and meaning & Secondary & 3 & $36,38,39$ \\
\hline context & Secondary & 4 & $30,32,33,35$ \\
\hline retention (memorization) & Secondary & 3 & $26,27,28$ \\
\hline
\end{tabular}

Table 5 illustrates the primary lexical chains which are nearly the same as what is shown in every section above. They are the chains "vocabulary", "strategy" and "learners". One detail found is that, in this section, the writers have not used "participants" to substitute learners, yet "participants" are adopted in the section of Methodology and Results. It is speculated that the sub-context shifts from Methodology towards Discussion/conclusion. In an empirical study, in the methodology, words like "participants" are usually suitable to the context of an experiment. But when the interpretation of the experiment finishes, the paper goes back to the general topics. The process from Introduction to Methodology is when LCCs dive into the water, while the one from Methodology towards Discussion/conclusion is when they emerge from the water. This metaphoric illustration corroborates the rhetoric structure that Glasman-Deal (2010) clarified.

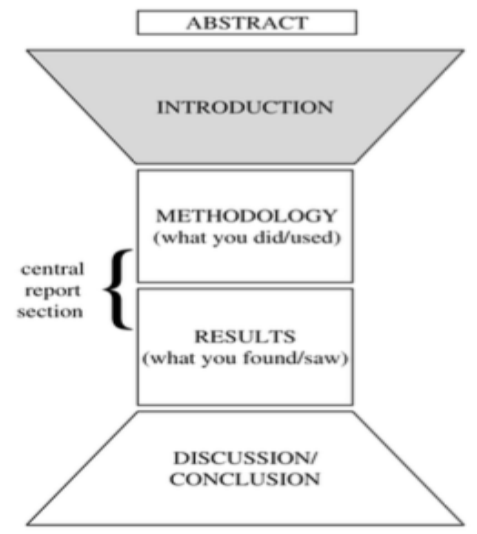

Figure 1. IMRD Structure

Extracted from Glasman-Deal (2010)

From a situated view, the choice of LC is determined by its context. It is a reflection of a situated view. Introduction and Discussion/conclusion usually are more general than the middle sections. Yet Methodology is for introducing the experiment entirely, the explanation in results is directly based on the methodology part. For this reason, it is inevitable to use experimental vocabulary like "participant" in Results. 
That is why we found this word in the part of the results. The language return to the general level in the Discussion/conclusion part. From a dynamic view, the secondary lexical chains are around "form and meaning", "context" and "retention". Although the discussion/conclusion section is the last part of an article, the new information still pours in. Besides, "implicit" and "explicit" are two strategies just as what we have examined above, they attach to the primary lexical chains. To conclude, in this section, it is found that synonymy and repetition again form lexical chains, in the meanwhile, antonymy also joins in.

\subsection{Lexical Cohesive Chains in the Whole Article}

A lexical cohesive chain is adopted to reveal the features of LC as a whole. In the light of analysis on four sections, the primary lexical cohesive chain is salient that is "strategy-vocabulary-learners". They run through the whole text. In contrast to the broad structure "IMRD", they are the inner structure or the skeleton of the text. It prevents the text from getting off the topics. Compared with relatively static primary chains, secondary lexical cohesive chains are more dynamic. According to the analysis above, it shows that nearly every part contains new secondary chains which promote the flow of information. To conclude, the primary lexical cohesive chain is obliged to fix the structure of a text, while the secondary chain is for updating the text.

It is mentioned that repetition has the most significantly strong lexical force compared with the other four devices. Cohesive force cannot only be embodied in the use of each device but different sections. Based on the intensity of the cohesive devices, it is noticeable that the introduction section contains more lexical cohesive devices, while methodology basically less. This result is not out of expectation. Since Introduction, as the first section in the RA, demands lexical cohesive devices to smooth the information flow. Yet Methodology also contains fresh information especially about how the experiment is carried out, its specialty determines that it is much more similar to a "checklist" (Myers, 1985). A checklist is usually loosely bound.

In addition, in this RA, lexical cohesive chains are often constituted by synonymy and repetition. Although the participation of antonymy, hyponymy, meronymy cannot be neglected, they only occupy a small part in this RA. Just as illustrated in 4.1, the relatively high occurrence of antonymy in this RA is closely relevant to the contents of this article.

To sum up, from the holistic perspective of, an article is like an ecological system. Both writers and readers are supposed to regard it as a whole so that the information can be conveyed fluently. As for writers, keywords in an article should be distributed from the beginning to the end in an article. Only in this way do the readers realize what the focus of the article is. As for readers, if they try to read through the whole article, the efficient way to obtain useful information is to examine how LCCs develop in the whole article rather than only concentrate on a sub-section in an article.

\section{Conclusion}

The functions of LCC are identical with "conveyor belts" which can carry other lexical cohesion devices like hyponymy, synonymy or antonymy in the meantime. Basically, the chains can be divided into two types, primary chains and secondary chains. The former runs through the whole text, while the latter continually updates the information. The primary chains underscore the essential information that writers want to convey. Compared with the secondary, their contents are relatively fixed. The secondary ones are more dynamic but subordinate to the primary. Secondary chains signal to readers that the information keeps flowing and the sub-topics continuously shift. The combination of the both will prevent the articles from being off the subjects, meanwhile, promotes the new information to enter.

Through analyzing the chains in the whole article, the holistic view is embodied. If both readers and writers keep notice of the overall picture, they will not be distracted by the new information or get off the topic. Besides, each section has its features, so from a situated view, to efficiently receive new information still needs to notice how the sub-context changes constantly. The dynamic view is reflected in the use of LCCs, especially the secondary LCCs. They come in and out only in several lines. The interactive view connects readers with writers and reveals the importance of the contextual interaction in the using of LCCs. In all, using LCCs systematically requires the using of ecological views.

\section{Sponsoring Information}

This Article is Sponsored by the Seed Foundation of Innovation and Creation for Graduate Students in Northwestern Polytechnical University 


\section{References}

Carston, R. (2012). Word meaning and concept expressed. The Linguistic Review, 29. https://doi.org/10.1515/tlr2012-0022.

Danes, F. (1987). "Lexical relations.” In J. Petr, F. Danes, M. Grepl, \& Z. Hlavsa (Eds.), Mluvnice Cestiny III (pp. 703-705). Prague: Academia.

Divjak, D. \& Gries, S. (2006). Ways of trying in Russian: clustering behavioral profiles. Corpus Linguistics and Linguistic Theory, 2(1), 23-60.

Edmonds, P., and Hirst, G. (2002). Near-synonymy and lexical choice. Computational Linguistics.28 (2):105-145.

Garner, M., 2004. Language: An Ecological View. Peter Lang, Oxford.

Geeraerts, D. (2010). Theories of lexical semantics. Oxford: Oxford University Press.

Glasman-Deal, H. (2010). Science research writing for non-native speakers of English. London: Imperial College Press.

Guinda, C. S. (2015). Genres on the move: currency and erosion of the genre moves construct. Journal of English for Academic Purposes, 19, 73-87.

Gutwinski, W. (1976). Cohesion in literary texts: a study of some grammatical and lexical features of English discourse. Berlin: Walter de Gruyter.

Hyland, K. (2013). Disciplinary Discourses: Social Interactions in Academic Writing. Disciplinary Discourses. Ann Arbor: University of Michigan Press.

Hyland , K. (2006). English for Academic Purposes. New York: Routledge.

Hyland, K. (2000). Disciplinary discourses: Social interactions in academic writing. Harlow, UK: Pearson Education Limited, Longman.

Halliday, M. A. K. (1985). An Introduction to Functional Grammar. London: Edward Arnold.

Halliday, M. A. K. \& Hasan, R. (1976). Cohesion in English. London: Longman.

Knorr-Cetina, K. (1981). The manufacture of knowledge. Oxford: Pergamon Press.

Liu, D., \& Zhong, S. (2016). L2 vs. 11 use of synonymy: an empirical study of synonym use/acquisition. Applied Linguistics, 37(2), 239-261.

Lyons, J. (1995). Linguistic semantics: An introduction. New York: Cambridge University Press.

Martin, J. R. (1992). English text: system and structure. Loan/open Shelves.

McCarthy, M. (1988). "Some vocabulary patterns in conversation." In R. Carter \& M. McCarthy (Eds.), Vocabulary and Language Teaching (pp. 181-200). London \& New York: Longman.

Morris, J., \& Hirst, G. (2006). The subjectivity of lexical cohesion in text. 20, 41--48.

Myers, G. (1989). The pragmatics of politeness in scientific articles. Applied Linguistics, 10(1), 1e35.

Sinclair, J. (1991). Corpus, concordance, collocation. Oxford University Press.

Steffensen, S. V., \& Fill, A. (2014). Ecolinguistics: the state of the art and future horizons. Language Sciences, 41(41), 6-25.

Tanskanen, S.-K. (2006). Collaborating towards coherence: Lexical cohesion in English discourse. Amsterdam, Philadelphia: John Benjamins Publishing.

van Dijk, T. (2008). Discourse and context:A sociocognitive approach. New York, Cambridge: Cambridge University Press.

Winter, E. (1979). Replacement as a fundamental function of the sentence in context. Forum Linguisticum, 4, 95133.

Yang, R.Y. (2006). Application of Genre Analysis: Analysis of Research Articles in Applied Linguistics. Foreign Languages and Their Teaching. (10), 29-34.

Zhang, D.L. (2006). Principles of Discourse Coherence. Foreign Languages and Their Teaching. (10), 7-10. 